Volume 8, No.1.5, 2019

International Journal of Advanced Trends in Computer Science and Engineering

Available Online at http://www.warse.org/IJATCSE/static/pdf/file/ijatcse1781.52019.pdf

https://doi.org/10.30534/ijatcse/2019/1781.52019

\title{
Traffic Routing Optimization using Ant Colony Optimization
}

\author{
Norulhidayah Isa $^{1}$, Muhammad Shariz Sharifudin ${ }^{2}$ \\ Universiti Teknologi MARA \\ Faculty of Computer and Mathematical Sciences \\ Terengganu Branch, Kuala Terengganu Campus, Malaysia \\ 1 norul955@uitm.edu.my, ${ }^{2}$ muhdshariz96@gmail.com
}

\begin{abstract}
Traffic congestion is one of the main problems in traffic system and it occurs on most cities around the world. This project focuses on solving recurring congestion that occurs in area around Kuala Terengganu city. Traffic routing can be implemented to reduce traffic congestion by finding the best path for a vehicle. Ant Colony Optimization algorithm is applied to optimize traffic routing in this project. Ant Colony Optimization (ACO) takes inspiration from the foraging behavior of some ant species and these ants release pheromone on the ground in order to mark some favorable path that should be followed by other ants. Simulation of Urban Mobility (SUMO) is used for the simulation of traffic congestion and traffic routing. Traffic Control Interface (TraCI) gives the program that is written in Python to access the traffic while the simulation is running and it allows to retrieve values of road travel time and to re-route a vehicle based on the path that is found by ACO. The efficiency of ACO is compared with Dijkstra algorithm. It is found that average travel time for vehicle simulation in ACO perform $30 \%$ faster than Dijkstra.
\end{abstract}

Key words: ant colony, congestion, optimization, routing.

\section{INTRODUCTION}

Traffic congestion is one of the main problems in traffic system and this problem occurs on most cities around the world. This causes a longer vehicle travel times, increased energy consumption, growing environmental pollution, reduced traffic safety, and a decrease in the efficiency of transportation infrastructure [1].

Traffic routing is a complex task which included finding the optimized path for a user, at a specific time. As there are many objectives and factors that can affect the efficiency of locating the shortest path to a goal, this make the traffic routing issue substantially harder [3]. It is essential for drivers to have sufficient knowledge to know the route to go to their desired destination. Traffic routing in urban areas and cities is mainly used to reduce congestion where traffic jam has turned out to be a standout problem in developing nations due to the fast development of economy and populace [6].

Traffic congestion that occurs in Central Business District can last for hours due to heavy traffic. Most drivers that stuck in the heavy traffic prefer to use another route with less traffic. Every intersections and junctions offer other routes that may have lesser traffic amount for driver to go to. However, they have no accurate information about selecting the best route to go to their destination. Algorithm like Ant Colony Optimization can provide a solution by calculating the probabilities of choosing the next road that is less congested.

\section{RELATED WORK}

Several objectives can be sometimes in contradiction when dealing with traffic routing problems. From the point of view of a driver, the aim of traffic routing is to search for the most optimal path between two nodes. So, the driver does not need to change routes [2]. Another goal is to maximize the flow of traffic and to optimize the utilization of the route and minimize the average travel time [2]. However, these two goals contradict to each other as it is hard to employ in dynamic environment [7].

Several papers in the past have already implemented ant colony optimization in solving traffic routing and optimization problem. Ant colony is an biological inspired computation algorithm that imitates ant natural behavior in finding the best path [18-19]. Reference [9] used the ACO for capacity restraint traffic assignment where a deterministic approach is combined based on a congestion function that reflects the link capacity.

Another approach of traffic routing was introduced by [8], where the road system is separated into several smaller sectors that is less complex and interconnected into a hierarchy of roads. There are three kinds of ants are used to route the traffic. First, are the local ants are used to maintain routes in a sector or to nearest node in neighboring sector. Second, is the backward ant that is used to update routing information that is kept at each of the nodes and lastly, is the exploring ants which is released to search and maintain routes in a sector.

Reference [2] implements the ACO to control network equilibrium dynamically and to optimize flow of traffic. In this research, they have designed a fitness function that aims the conflicting goals of user equilibrium and system optimum with the help of three objectives which are: 1) to keep the flows under known capacity, 2) to keep the difference between fastest and slowest route below given threshold, and 3) to fully utilize the fastest route. 
Norulhidayah Isa et al., International Journal of Advanced Trends in Computer Science and Engineering, 8(1.5), 2019,81 - 86

\subsection{Variables in Ant Colony Optimization}

In order to solve traffic routing problem, several variables are taken into account, which are nodes (n), edges (e), travel time $(\mathrm{tt})$, speed (s) and distance (d). The variables are listed in the Table 1 below.

Table 1: Variables for traffic routing

\begin{tabular}{|c|c|c|c|c|c|c|}
\hline \multirow{2}{*}{ Ref. } & \multirow{2}{*}{ Algorithm Used } & \multicolumn{5}{|c|}{ Variable } \\
\hline & & $\mathbf{S}$ & $\mathbf{t t}$ & d & $\mathbf{e}$ & $\mathrm{n}$ \\
\hline [7] & $\begin{array}{l}\text { Ant Colony } \\
\text { Optimization }\end{array}$ & $\checkmark$ & & $\checkmark$ & $\checkmark$ & $\checkmark$ \\
\hline [3] & $\begin{array}{l}\text { Ant Colony } \\
\text { Optimization }\end{array}$ & & $\checkmark$ & & $\checkmark$ & $\checkmark$ \\
\hline [10] & Greedy Algorithm & & & $\checkmark$ & $\checkmark$ & $\checkmark$ \\
\hline [11] & $\begin{array}{l}\text { Ant Colony } \\
\text { Optimization, } \\
\text { Genetic Algorithm }\end{array}$ & & $\checkmark$ & $\checkmark$ & $\checkmark$ & $\checkmark$ \\
\hline [12] & $\begin{array}{l}\text { Ant Colony } \\
\text { Optimization }\end{array}$ & & $\checkmark$ & $\checkmark$ & $\checkmark$ & $\checkmark$ \\
\hline [13] & Genetic Algorithm & & $\checkmark$ & $\checkmark$ & $\checkmark$ & $\checkmark$ \\
\hline$[15]$ & $\begin{array}{ll}\text { Artificial } & \text { Neural } \\
\text { Network } & \end{array}$ & $\checkmark$ & & & $\checkmark$ & $\checkmark$ \\
\hline [16] & $\begin{array}{l}\text { Hybrid } \\
\text { Algorithm }\end{array}$ & $\checkmark$ & $\checkmark$ & $\checkmark$ & $\checkmark$ & $\checkmark$ \\
\hline [14] & $\begin{array}{l}\text { Ant Colony System, } \\
\text { Fuzzy Inference } \\
\text { System }\end{array}$ & $\checkmark$ & & $\checkmark$ & $\checkmark$ & $\checkmark$ \\
\hline [2] & $\begin{array}{l}\text { Ant Colony } \\
\text { Optimization }\end{array}$ & $\checkmark$ & & $\checkmark$ & $\checkmark$ & $\checkmark$ \\
\hline
\end{tabular}

The use of edges and nodes as the variables is the most parameter in traffic routing. Other variables are important in its own algorithm, such as speed in Ant Colony Optimization algorithm is not necessary as some research done is to reduce the congestion level regardless the time taken to solve it.

\subsection{Major steps in Ant Colony Optimization}

There are four major steps in Ant colony optimization algorithm which are:

\section{Step 1: Ant Initialization:}

ACO solves problems by mapping the environment into a graph with nodes and routes (edges). At the beginning of the ant colony search process, a number of ants are placed in different original nodes. The generation of a new path requires the use of initial ant, which is an agent that establishes the pheromone track to a source node [4]. A node creates a record in the routing table if it receives an initial ant for the first time.

\section{Step 2: Ant probability for Node Selection:}

Increasing ant activity will increase the probability of selecting a preferred path until almost all ants choose the preferred path to traverse from one node to another. Then, ants move from their source region $i$ to the next region $j$, which then move to another region [5]. Пij represents the edge cost experienced by an ant in traveling from one region to another, whereas $\tau$ ij simulates the concentration of the trail on edge $(\mathrm{i}, \mathrm{j})$. Transition probability can be defined using (1):

$$
P_{i j}^{k}(t)=\frac{\left(\tau_{i j}\right)^{\alpha} \eta_{i j} \beta}{\sum_{h \notin t a b u_{k}}\left(\tau_{i h}\right)^{\alpha} \eta_{i h}{ }^{\beta}}
$$

\section{Step 3: Pheromone update:}

The value of pheromones in a trail is updated at the end of each cycle which called as pheromone update once each ant has obtained a route [4] as shown in (2):

$$
\tau_{i j}^{\text {new }}=(1-p) \tau_{i j}^{\text {old }}+\sum_{k=1}^{m} \Delta \tau_{i j}^{k}
$$

Pheromone evaporation $(\rho)$ value is a fixed number between 0 and 1 . The concentration of pheromone of ant $\mathrm{k}$ on a specific edge(i,j) can be calculated using (3) :

$$
\Delta \tau_{i j}^{k}=\frac{Q}{f_{k}}
$$

\section{METHODOLOGY}

\subsection{Traffic Simulation and Representation}

In this research, Simulation on Urban Mobility is used to represent the traffic situation. Simulation of Urban Mobility (SUMO) is an open source, highly portable, microscopic and continuous road traffic simulation package designed to handle large road networks supports different types of transportation vehicles [17]. In this research, traffic congestion is simulated in SuMO before the ACO algorithm is executed.

SuMO uses travel time as its default metric to calculate the movement of vehicle in roads. For this project, the higher the vehicle amount in a specific road, the higher the travel time for a vehicle to traverse in the road. Travel time is used as the objective function for the optimization process.

The data map for traffic network of Kuala Terengganu city is imported from openstreetmap.org website as shown in Figure 1. A simple version of the network will be taken as the focus of this project is to get the routing results from the algorithm rather than the precision of the network. The map dimension is $4 \mathrm{~km} \mathrm{x} 3 \mathrm{~km}$ and the area for the map is $12 \mathrm{~km}^{2}$. The average length of each road in the map is around $1.5 \mathrm{~km}$.

A connection for each junction that was extracted from SuMO is represented in an adjacency matrix as shown in Figure 2. The value represents the distance in meter. 


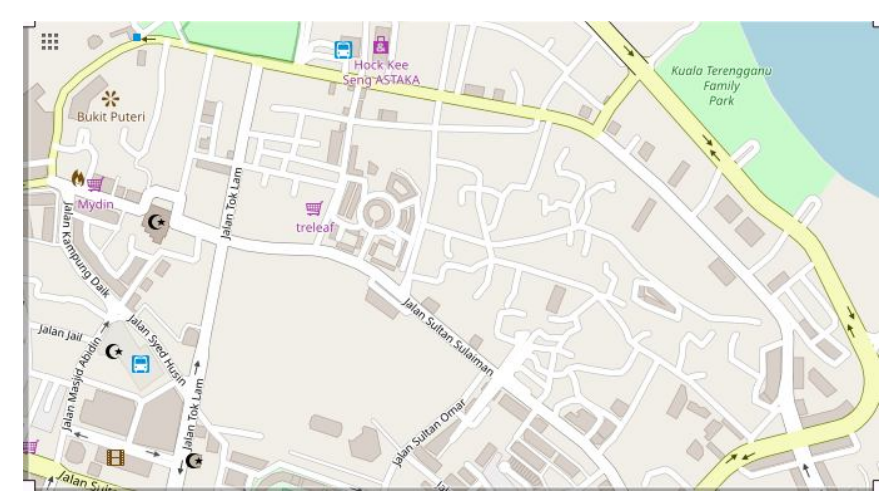

Figure 1: Data map for Kuala Terengganu traffic network

\begin{tabular}{|c|c|c|c|c|c|c|c|c|c|}
\hline Nodes & J1 & J2 & J3 & J4 & J24 & J25 & J26 & J27 & J28 \\
\hline J1 & 0.0 & 190.84 & 0.0 & 83.43 & 0.0 & 0.0 & 0.0 & 0.0 & 0.0 \\
\hline J2 & 0.0 & 0.0 & 115.96 & 0.0 & 0.0 & 0.0 & 0.0 & 0.0 & 0.0 \\
\hline J3 & 0.0 & 0.0 & 0.0 & 0.0 & 0.0 & 0.0 & 0.0 & 0.0 & 0.0 \\
\hline J4 & 0.0 & 0.0 & 0.0 & $\mathbf{0 . 0}$ & 0.0 & 0.0 & 0.0 & 0.0 & 0.0 \\
\hline J24 & 0.0 & 0.0 & 0.0 & 0.0 & 0.0 & 209.95 & 0.0 & 238.00 & 0.0 \\
\hline J25 & 0.0 & 0.0 & 0.0 & 0.0 & 0.0 & 0.0 & 166.90 & 0.0 & 0.0 \\
\hline J26 & 0.0 & 0.0 & 0.0 & 0.0 & 0.0 & 0.0 & 0.0 & 197.58 & 0.0 \\
\hline J27 & 0.0 & 0.0 & 0.0 & 0.0 & 0.0 & 0.0 & 0.0 & 0.0 & 124.56 \\
\hline J28 & 0.0 & 0.0 & 0.0 & 0.0 & 0.0 & 0.0 & 0.0 & 0.0 & 0.0 \\
\hline
\end{tabular}

Figure 2: Adjacency matrix of junctions

\subsection{Ant Colony Algorithm Implementation}

Figure 3 shows the flow of the process of the methodology used in this project. Parameters such as ant numbers, number of generations, alpha value, beta value, pheromone intensity are initialized. Alpha value represents the importance of pheromone, beta represent the importance of weight which in this case is the travel time. An initial value of pheromone is initialized in each route by using the formula;

$$
\tau_{i j}=\frac{1}{\text { rank } * \text { rank }}
$$

Ant starts from a source node which in this case is ' $\mathrm{j} 1$ ' and travel to destination which is ' $\mathrm{j} 27$ '. Next node is chosen based on the amount of pheromone concentration on the edge and the weight (travel time) using the formula in (5). The higher the probability value means that the edge is likely to be chosen by the ants.

$$
P_{i j}=\frac{\tau_{i j} \alpha_{*} \eta_{i j} \beta}{\sum \tau_{i j} \alpha_{*} \eta_{i j} \beta}
$$

Where:

$$
\eta_{i j}=\frac{1}{\text { travel time }_{i j}}
$$

The value of pheromone in an edge is updated in every ant using the formula, where $\mathrm{Q}$ is equal to the amount of pheromone that an ant releases:

$$
\tau_{i j}=\frac{Q}{\text { travel time }_{i j}}
$$

A total cost for a route that consists of a set of best edges is calculated. Each ant has their own total cost when they traveled through the graph. The best edge is taken from the best ant among the total ants that has the minimum total cost. The value of pheromone in the graph is updated after all of ants traversed and released their own pheromone in each edges.

The algorithm will terminate if the iteration is equal to $n$ where $\mathrm{n}$ is the number that is set within the experiment.

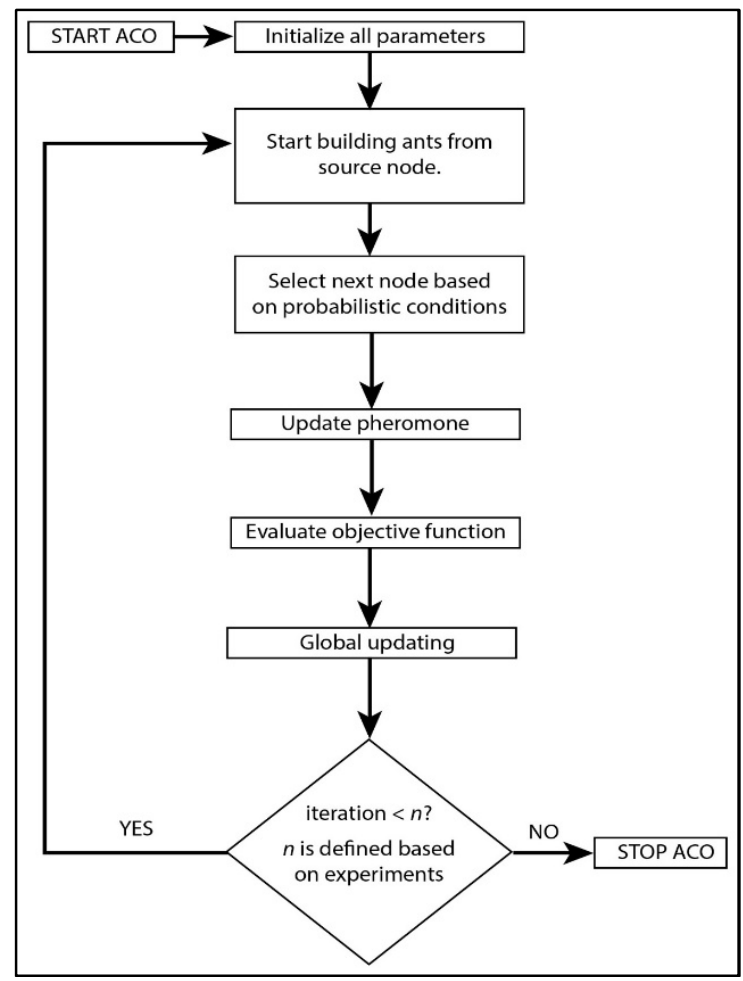

Figure 3: Flow of ACO in this project.

\section{RESULTS AND EVALUATION}

After the simulation that is done in SUMO. A route is generated and a vehicle is created to travel the road is the most optimized as shown in Figure 5. The blue line in figure 5 represents the new generated path.

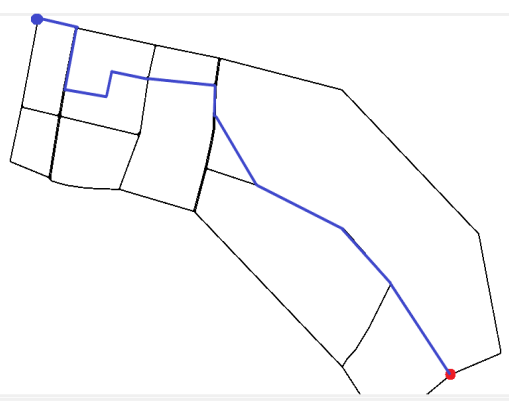

Figure 5: Route that is generated after ACO is applied 
Ant colony optimization consists of several parameters such as ant numbers, generations, $\alpha, \beta, \zeta$, and $\lambda$ in its formulation to find the optimized route and the performance of the algorithm depends on these parameters. As a start, these values are tuned and experimented to find the suitable values that is suited for this project.

To find the suitable value for $\alpha$ and $\beta$ there must be a trade-off such as the value of $\alpha+\beta=1$. For this project the suitable value is $\alpha=0.6$ and $\beta=0.4$, it is because the ants are more inclined to follow the pheromone that are released on the edges. Figure 6 shows the average travel time by ants when the two parameters $\alpha$ and $\beta$ are changed. The average travel time when changing the parameters are between 200 s to $268 \mathrm{~s}$ at the beginning where the value of $\alpha$ is between 0 to 0.2 where value $\beta$ is between 0.8 to 1 . At the end, the value changed to $\alpha$ is between 0.8 to 1 while $\beta$ is between 0 to 0.2 .

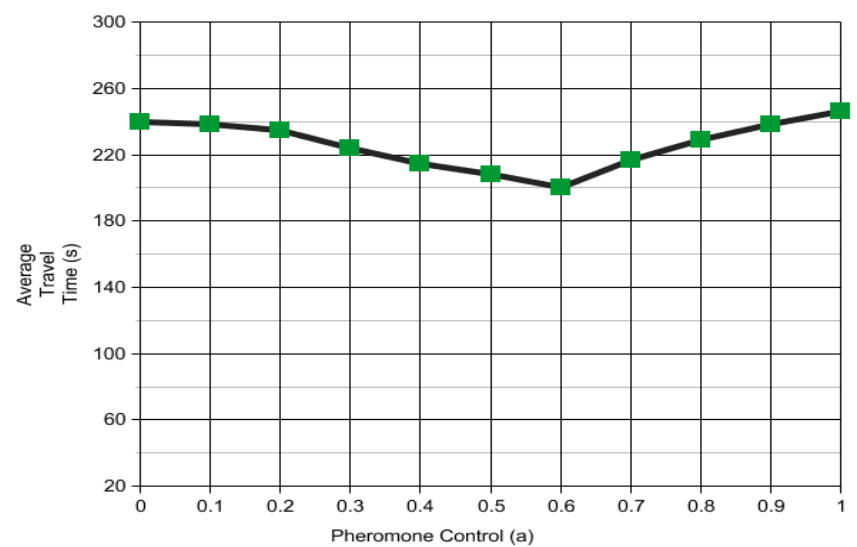

Figure 6: Average travel time (s) with pheromone control $(\alpha)$ values.

Pheromone evaporation plays an important part in this algorithm as it affect in the way how the total pheromone in the graph is updated and this is related to the convergence speed of the algorithm. Varieties of values are examined to find the most suited value of this parameter and the result is shown at Figure 7. When the value of $\rho$ is low, the speed of convergence is higher as the pheromones evaporate slower in each of the edges and the convergence speed is slower when the value of $\rho$ is higher because the pheromone evaporation happens faster. The most suited value found for $\rho$ value is $\rho=$ 0.3 .

The finding of the path is done by using ants that are released for route traversal. An origin number of ants is predefined at the start of the initialization of the algorithm. For this project, $1-10$ ants are tested as shown in Figure 8. The average travel time and execution time are calculated for every increment in ant numbers. The lowest average travel distance is found at ant number $=5,6,7,8,9$ and 10 but the execution number for ant number $=5$ is lower than the other.

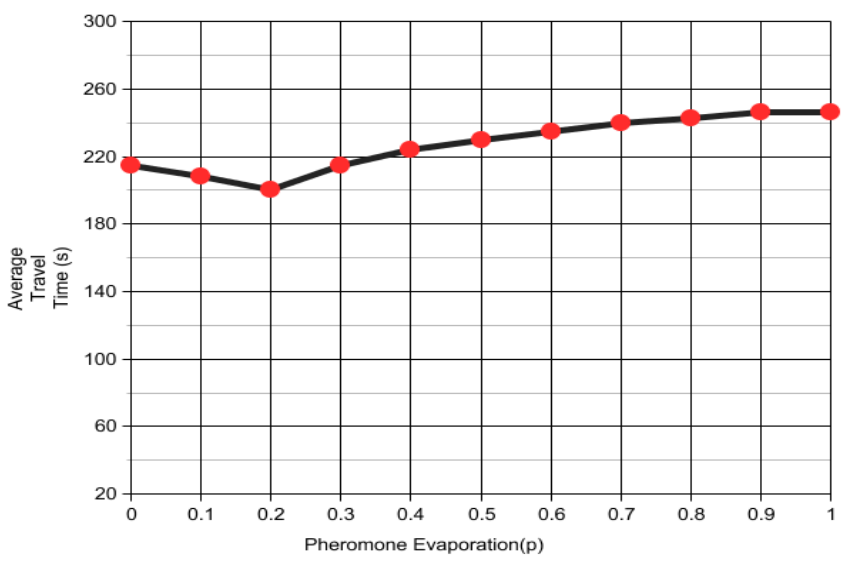

Figure 7: Average travel time (s) with pheromone evaporation $(\rho)$.

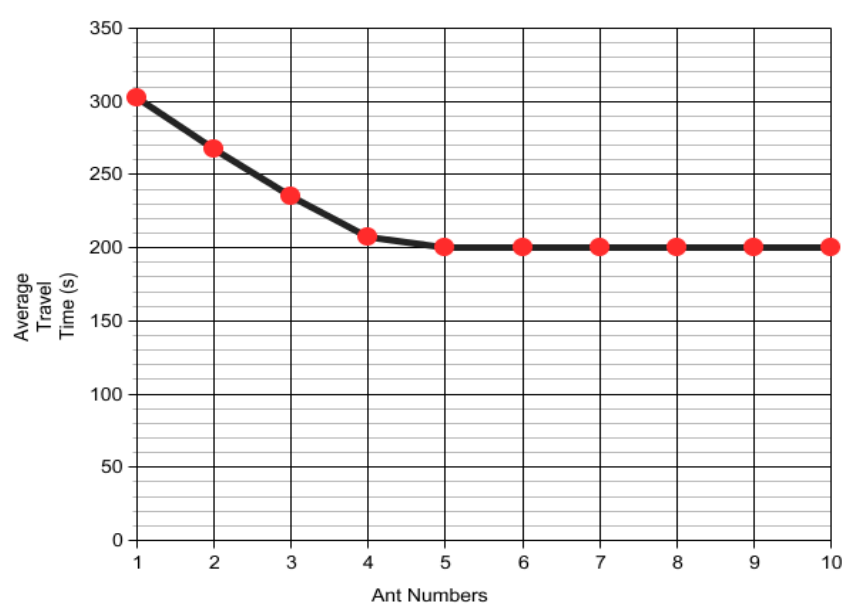

Figure 8: Average travel time (s) with ant numbers

The number of generations is also predefined at the start of the initialization process. For this experiment the iteration value is tested between 20 to 100 as shown in Figure 9. The ant number in this experiment is set to a constant of 5 ants and the lowest average travel time is found at 100 generations.

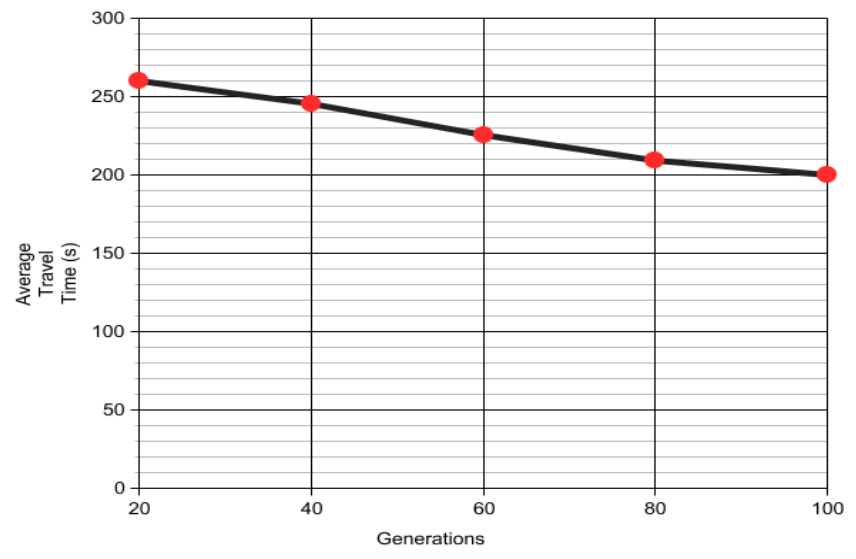

Figure 9: Average travel time (s) with generations numbers 


\subsection{Comparison between ACO and Dijkstra algorithm}

Dijkstra is a greedy method to solve single source shortest path problem. It chooses the optimum path at each stage to find the global optimum solution. The selection of unselected nodes, current node to next node is done repeatedly and declares the distance to be actual shortest distance from current node to next node. The edges are first checked to make sure that the target destination can be reached from current node followed by the relevant outgoing edges. Dijkstra algorithm is selected as a comparison algorithm as it is one of the popular algorithms in finding shortest path in traffic routing.

It is well suited to routing in time-dependent networks. In comparison of ACO and Dijkstra algorithm, ACO algorithm improves the average travel time where it prefers the route that has lower volume of traffic. The table 2 below shows that, when ACO is applied, the average distance traveled is increased by $11 \%$ than using Dijkstra algorithm. However, the average travel time for ACO algorithm is lower than Dijkstra algorithm by $30 \%$. This is preferable because even if the route is longer, the volume of congestion is lower thus making the travel time to be decreased. The route traversal from source node to destination is much faster.

Table 2: Average travel time and travel distance for ACO and Dijkstra algorithm.

\begin{tabular}{|c|c|c|}
\hline Metrics & ACO & Dijkstra \\
\hline Avg. Travel Time (s) & 200.0 & 268.0 \\
\hline Avg. Travel Distance (m) & 1441.18 & 1308.78 \\
\hline
\end{tabular}

\section{CONCLUSION}

This project is beneficial for traffic routing in urban area which has more complex type of road because traffic congestion always occurs in urban area due to the increase traffic vehicles. This routing project can also be implemented in a larger scale and scope such as developing a routing for a whole traffic network in a country. This project contributes mostly to the people who lives in Kuala Terengganu as the datasets that were obtained are based on the road network in Kuala Terengganu city especially in the Central Business District (CBD) area. The performance metrics and data that were discussed in this project can also contributes to for future researches and projects that can use them as a comparison. The algorithm that was proposed in this project can also be implemented with different city road network, which has and Networks, ICCCN. https://doi.org/10.1109/ICCCN.2014.6911771

11. Doriya, R., Wadhwa, N., Suraj, K., Chakraborty, P., \& Nandi, G. C. (2014). Dynamic Vehicle Traffic Routing Problem : Study, Implementation and Analysis using ACO and GA, 1302-1309.

12. Goudarzi, F., Asgari, H., Member, S., Al-raweshidy, H. S., \& Member, S. (2018). Traffic-Aware VANET different complexity and traffic level. Traffic routing experiment was done in SUMO and TraCI tools. This project can benefit others who want to implement the same simulator software and its tools.

\section{REFERENCES}

1. Abdul, K., \& Jomaa, R. (2016). An Artificial Intelligence Techniques and Simulation Model to Control a Traffic Jam System in Malaysia ( Review Paper ), 04(01), 27-34.

2. Alves, D., Ast, J. Van, Cong, Z., Schutter, B. De, Babu, R. (2010). Ant Colony Optimization for Traffic Dispersion Routing. Transportation, 19, 683-688.

3. Burrows, P., Reed, K., Templer, K., \& Walker, J. (2011). Efficient Traffic Routing using ACO, 1-26. Retrieved from http://www.cs.bham.ac.uk/ rjh/courses/NatureInspiredD esign/2011-12/index.htm

4. Günes, M., Sorges, U., \& Bouazizi, I. (2002). ARA The Ant-Colony Based Routing Algorithm for MANETs. ICPPW '02 Proceedings of the 2002 International Conference on Parallel Processing Workshops, (November),79-85. https://doi.org/10.1109/ICPPW.2002.1039715

5. Jabbarpour, R. M., Malakooti, H., Md Noor, R., Anuar, N. B., \& Khamis, N. (2014). Ant colony optimisation for vehicle traffic systems: applications and challenges, $6(1), 32-56$.

6. Lu, D. (2017). A Novel Traffic Routing Method Using Hybrid Ant Colony System Based on Genetic Algorithm, 584-589.

7. Kromer, P., Martinovic, J., Radecky, M., Tomis, R., \& Snasel, V. (2011). Ant colony inspired algorithm for adaptive traffic routing. Proceedings of the 2011 3rd World Congress on Nature and Biologically Inspired Computing, NaBIC 2011, 329-334. https://doi.org/10.1109/NaBIC.2011.6089614

8. Tatomir, B., \& Rothkrantz, L. (2006). Hierarchical Routing in Traffic Using Swarm-Intelligence. 2006 IEEE Intelligent Transportation Systems Conference, 230-235. https://doi.org/10.1109/ITSC.2006.1706747

9. Xu, Z., Sun, H., Li, X., Chen, D., \& Yu, S. (2008). Ant colony optimization arithmetic of capacity restraint traffic assignment. Proceedings of the IEEE International Conference on Automation and Logistics, ICAL 2008, (September),972-976. https://doi.org/10.1109/ICAL.2008.4636291

10. Song, Y., \& Liu, M. (2014). Greedy-based distributed algorithms for green traffic routing. Proceedings International Conference on Computer Communications

Routing for City Environments - A Protocol Based on Ant Colony Optimization, 1-11.

13. Lu, B. J., Wang, T., \& Wu, L. L. (2011). Research on military traffic and transportation path optimization based on genetic algorithm. Proceedings 2011 International Conference on Mechatronic Science, Electric Engineering and Computer, MEC 2011, 1549-1551. https://doi.org/10.1109/MEC.2011.6025769 
14. Lisangan, E. A., \& Sumarta, S. C. (2017). Route Selection Based on Real Time Traffic Condition Using Ant Colony System and Fuzzy Inference System, 66-71.

15. Fang, M., Zhu, G., Zheng, X., \& Yin, Z. (2011). Study on air fine particles pollution prediction of main traffic route using artificial neural network. Proceedings - International Conference on Computer Distributed Control and Intelligent Environmental Monitoring, CDCIEM 2011, 1346-1349. https://doi.org/10.1109/CDCIEM.2011.431

16. Kim, K. T., \& Jeon, G. (2010). A vehicle routing problem considering traffic situation with time windows by using hybrid genetic algorithm. The 40th International Conference on Computers \& Indutrial Engineering, $1-6$.
17. Krajzewicz D., Erdmann J., Behrisch M., and Bieker L. Recent Development and Applications of SUMO Simulation of Urban MObility; International Journal On Advances in Systems and Measurements, 5 (3\&4):128-138, December 2012.

18. Reddy, S. V., \& Swathi, S. Optimal Allocation and Sizing of multiple Distributed Generation in distribution network by Ant Colony Search Algorithm. International Journal of Advanced Trends in Computer Science and Engineering, Vol. 3 , No.1, Pages : 59 - 63 (2014)

19. D. Hema Latha and P. Premchand., Estimating Software Reliability Using Ant Colony OptimizationTechnique with Salesman Problem for Software Process. International Journal of Advanced Trends in Computer Science and Engineering, 7(2), March -April 2018, 20- 29 